\title{
Effects of the Nanostructured Fe-V-Nb Modificators on the Microstructure and Mechanical Properties of Si-Mn Steel
}

\author{
Tiebao Wang, Chunxiang Cui, Kuo Jia, and Lichen Zhao \\ School of Materials Science and Engineering, Hebei University of Technology, No.8 Guangrong Road, Hongqiao District, \\ Tianjin 300130, China \\ Correspondence should be addressed to Chunxiang Cui, hutcui@hebut.edu.cn
}

Received 20 May 2012; Revised 24 July 2012; Accepted 25 July 2012

Academic Editor: Alireza Khataee

Copyright ( 92012 Tiebao Wang et al. This is an open access article distributed under the Creative Commons Attribution License, which permits unrestricted use, distribution, and reproduction in any medium, provided the original work is properly cited.

The nanostructured Fe- $\mathrm{V}-\mathrm{Nb}$ master alloy was prepared in vacuum rapid quenching furnace and then was added in the steel melts as modificators before casting. Next, the effects of the nanostructured Fe- $\mathrm{V}-\mathrm{Nb}$ modificators on the microstructure and mechanical properties of the steel were studied. The results show that the grain size of the steel has been effectively refined, which is mainly because the dispersed nanoscale particles can produce more nucleation sites during the solidification of the liquid steel. Tensile properties and fracture morphology reveal that the yield strength and toughness of the steel modified by nanostructured Fe- $\mathrm{V}-\mathrm{Nb}$ modificators are better than that of the microalloyed steel. TEM analysis shows that vanadium and niobium in the modificators exist in the form of $(\mathrm{V}, \mathrm{Nb}) \mathrm{C}$ which effectively increases the nucleation rate and leads to better mechanical properties of the steel.

\section{Introduction}

With the rapid development of automobile, the demand for spring steels with higher performance is growing rapidly. At present, most automotive springs are made of the medium carbon high-strength steels obtained after the quenching and tempering [1]. To achieve the desired mechanical strength, the most commonly method used is to add alloying elements such as vanadium and niobium [2], the carbonitride of which may refine the grain size of austenite and act as the strengthening precipitates [3]. As a result, a high strength and good sag resistance can be achieved [4]. To further optimize the mechanical properties of medium-carbon martensitic steels, nanostructured $\mathrm{Fe}-\mathrm{V}-\mathrm{Nb}$ master alloy can be added into the steel as modificators. However, there are few reports on the systematic investigations about the effect of the nanostructured $\mathrm{Fe}-\mathrm{V}-\mathrm{Nb}$ modificators [5-7]. So, as a basic study, it is necessary to uncover the interaction between modificators and the steels through a series of experiments, especially the effect of modificators on the refinement of grains.

In this study, the nanostructured $\mathrm{Fe}-\mathrm{V}-\mathrm{Nb}$ modificators were prepared by melt-spin method and the effect of the modificators on the mechanical properties of Si-Mn spring steels was studied. Furthermore, the detailed information on the relationship between the mechanical properties and the microstructure has also been clarified by means of scanning electron microscopic (SEM) and transmission electron microscope (TEM) observations.

\section{Experimental Procedure}

The raw material used in this study was commercial SiMn steel (hereafter denoted as steel A). Nanostructured Fe$\mathrm{V}-\mathrm{Nb}$ modificators were prepared by rapid quenching in vacuum with the rolling wheel speed of $45 \mathrm{~m} / \mathrm{s}$. Steel A was firstly melted in the vacuum induction furnace, then the nanostructured $\mathrm{Fe}-\mathrm{V}-\mathrm{Nb}$ modificators were added to the melt before casting. The melts were poured at about $1600^{\circ} \mathrm{C}$ accompanied by stirring and then the ingots were forged into bars with a size of about $25 \mathrm{~mm}$ in diameter (hereafter denoted as steel c). As a comparison, the steel microalloyed with $\mathrm{V}$ and $\mathrm{Nb}$ (hereafter denoted as steel $\mathrm{B}$ ) was also prepared. The chemical compositions of the experimental steels were listed in Table 1 . All of the forged bars of steels that have been quenched at $860^{\circ} \mathrm{C}$ and tempered at $350-550^{\circ} \mathrm{C}$ were machined into specimens for the mechanical test and microscopic observation. 


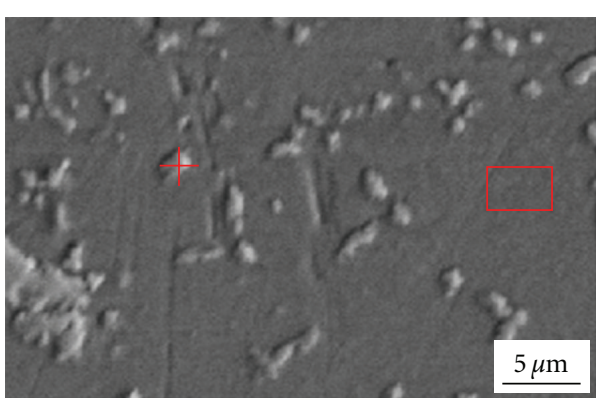

(a)

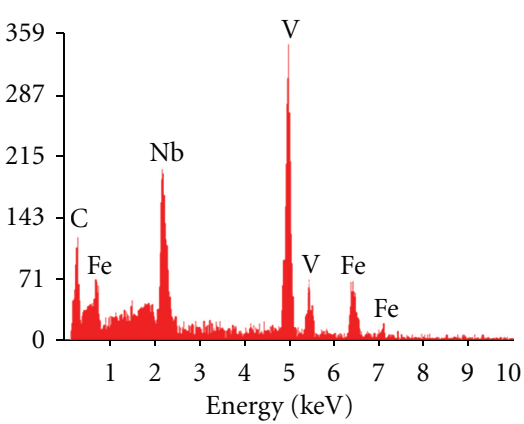

(b)

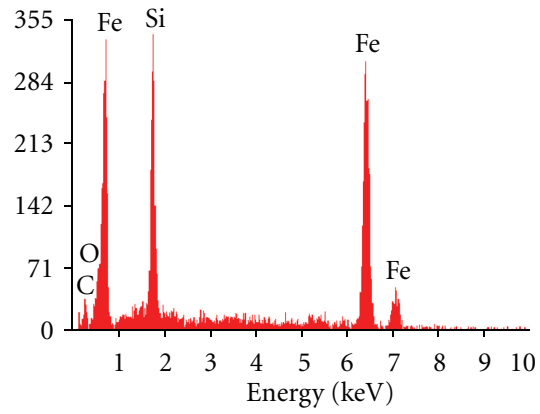

(c)

FIGURE 1: (a) SEM image of the melt-spin Fe-V-Nb modificators; (b) an EDS spectrum of the white-color phase in Fe-V-Nb modificators as indicated by a cross in (a); (c) an EDS spectrum of the matrix phase as indicated by a rectangle in (a).

TABle 1: Chemical compositions of the experimental steels (Wt.\%).

\begin{tabular}{lcccccccc}
\hline \multirow{2}{*}{ Steels } & \multicolumn{8}{c}{ Element contents } \\
& $\mathrm{C}$ & $\mathrm{Si}$ & $\mathrm{Mn}$ & $\mathrm{S}$ & $\mathrm{P}$ & $\mathrm{Cr}$ & $\mathrm{Nb}$ & $\mathrm{V}$ \\
\hline Steel A & 0.59 & 1.84 & 0.81 & 0.002 & 0.008 & 0.28 & - & - \\
Steel B & 0.61 & 2.00 & 0.95 & 0.002 & 0.010 & 0.27 & 0.05 & 0.04 \\
Steel C & 0.61 & 1.97 & 0.93 & 0.003 & 0.009 & 0.27 & 0.05 & 0.05 \\
\hline
\end{tabular}

Tensile tests were performed at ambient temperature with a tensile speed of $2 \mathrm{~mm} / \mathrm{s}$ on a screw-driven Instron Model SHT- 4505 test machine. Microstructure of the specimens was observed with the aid of optical microscope after etching in nital. A PhillipsXL30 SEM was used to analyze the fracture surfaces of the broken tensile specimens. A Phillips FEI Tacnai F20 transition TEM was also used to observe the microstructure of modificators and type of tempered carbides with an accelerating voltage of $200 \mathrm{kV}$. The compositions of individual carbonitride were determined by the energy dispersive X-ray spectroscopy (EDS).

\section{Results and Discussion}

3.1. Microstructure of $\mathrm{Fe}-\mathrm{V}-\mathrm{Nb}$ Modificators. Figure 1 shows the SEM image and EDS spectrum of the melt-spin Fe-V$\mathrm{Nb}$ modificators. The EDS spectrum in Figure 1(b) indicates that the white-color phase marked with a cross contains $\mathrm{V}$ and $\mathrm{Nb}$ elements together. However the EDS spectrum in Figure 1(c) shows that the matrix phase marked with a rectangle does not contain any $\mathrm{V}$ and $\mathrm{Nb}$ elements. The XRD pattern of the melt-spin $\mathrm{Fe}-\mathrm{V}-\mathrm{Nb}$ modificators is depicted in Figure 2. So it can be concluded from the XRD result that the white-color phase in the modificators is compound carbide, namely, $(\mathrm{V}, \mathrm{Nb}) \mathrm{C}$. The average grain size of the Fe$\mathrm{V}-\mathrm{Nb}$ modificators obtained is $33 \mathrm{~nm}$, which was calculated by Scherrer formula [8]. TEM micrograph and diffused electron diffraction pattern of the $\mathrm{Fe}-\mathrm{V}-\mathrm{Nb}$ modificators are shown in Figure 3. As shown in Figure 3, the melt-spin Fe$\mathrm{V}-\mathrm{Nb}$ is composed of nano-particles and in this part the TEM image displays a disordered arrangement of atoms and no diffraction spots appears in the electron diffraction pattern. Combined with the X-ray result, it can be concluded

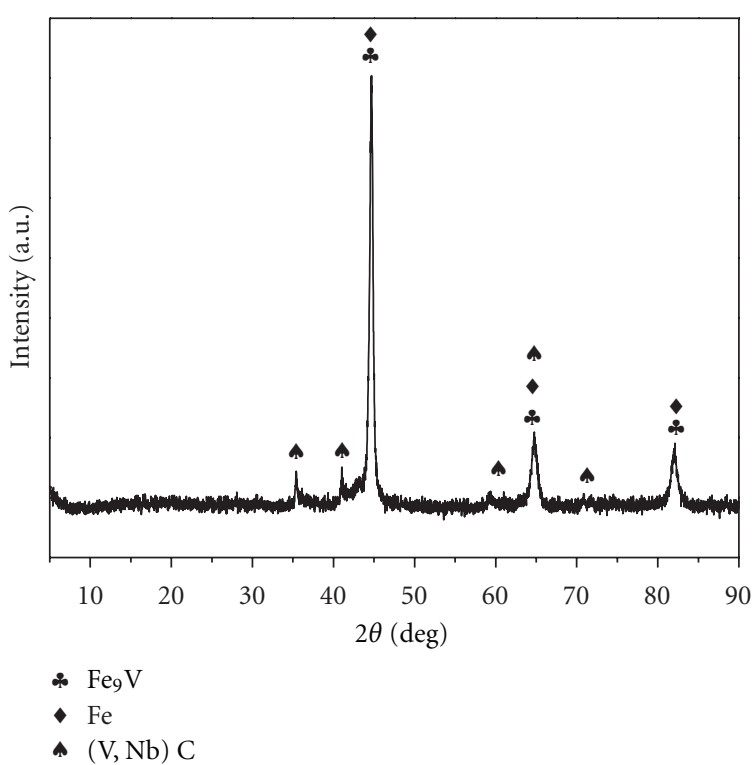

FIGURE 2: XRD parrten of Fe-V-Nb modificators.

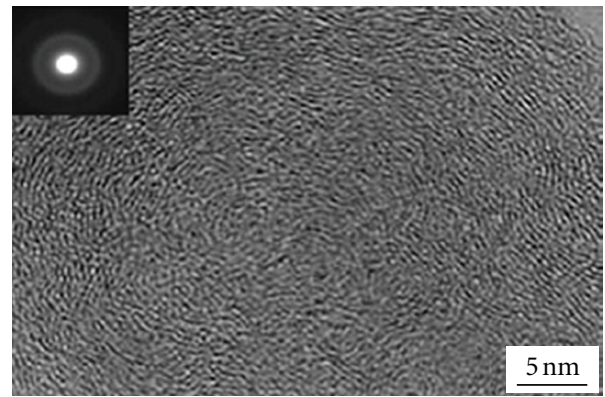

FIGURE 3: TEM micrograph and diffused electron diffraction pattern of $\mathrm{Fe}-\mathrm{V}-\mathrm{Nb}$ modificators.

that the Fe-V-Nb modificators should be composed of a high proportion of nano-crystallines and a little part of amorphous phases. 


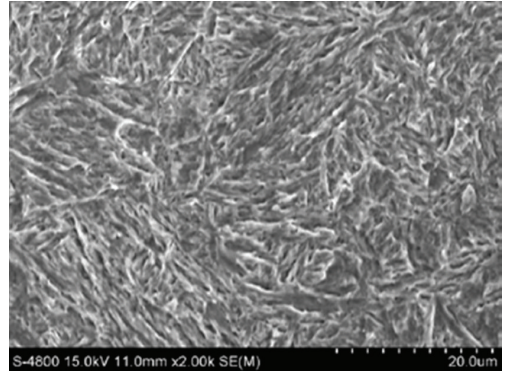

(a)

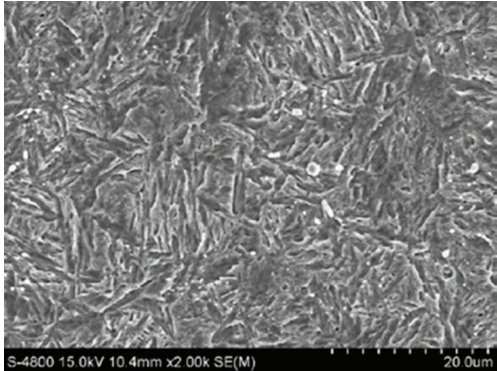

(b)

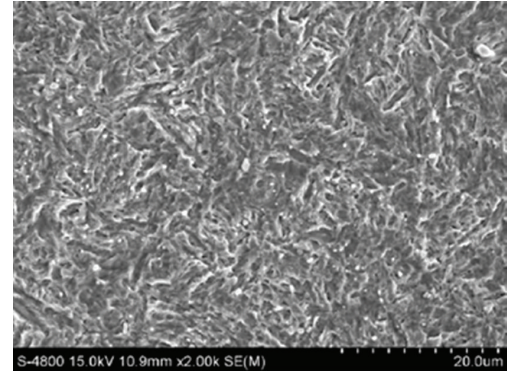

(c)

FIGURE 4: SEM micrographs of conventionally heat-treated sample quenched at $860^{\circ}$ C: (a) Steel A; (b) Steel B; (c) Steel C.

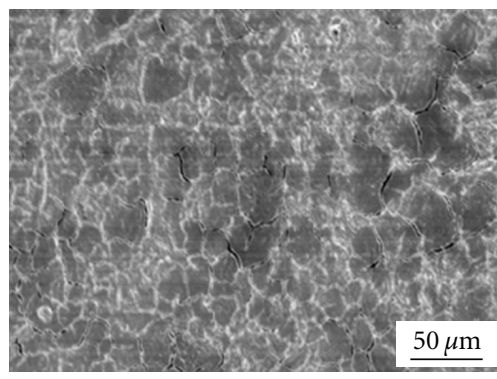

(a)

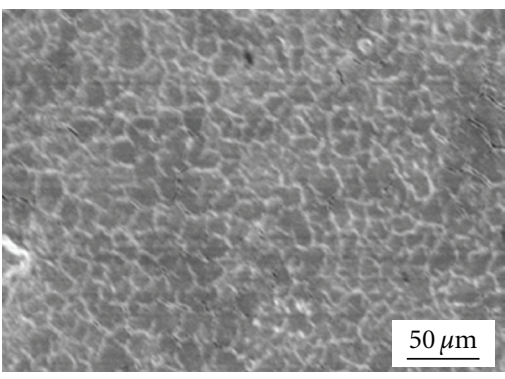

(b)

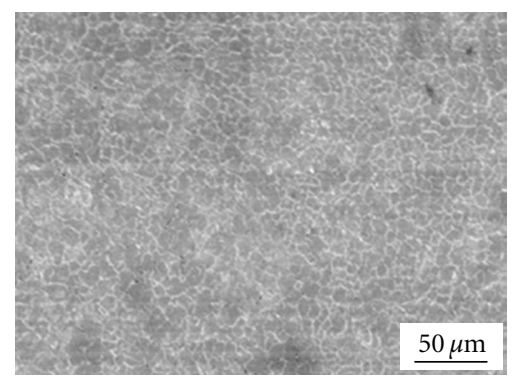

(c)

FiguRE 5: SEM micrographs of the prior austenite grain structures: (a) Steel A; (b) Steel B; (c) Steel C.

\subsection{Effect of Fe-V-Nb Modificators on the Microstructure of} Steels. Figure 4 shows the quenching structure of three types of steels, in which it can be seen that the microstructure consists of lath martensite and acicular martensite. Compared with steel A and B, steel C has the finest mixed martensites. It is well known that the thickness of lath martensite and the length of acicular martensite are mainly decided by the prior austenite grain size. The finer the prior austenite grain, the finer martensite obtained by quenching. Amongst the three steels, steel $\mathrm{C}$ has been found to have the finest prior austenite grain sizes (showing in Figure 5). The average prior austenite grain sizes of steel A, steel B, and steel C are about $30 \mu \mathrm{m}, 20 \mu \mathrm{m}$, and $10 \mu \mathrm{m}$, respectively. It is apparent that the prior austenite grain sizes of steel $\mathrm{B}$ and steel $\mathrm{C}$ are more homogeneous than that of steel A. Due to the pinning effect of the vanadium and niobium carbides on the grain boundaries, the addition of the microalloying elements can refine the austenite grain sizes to some extent. However, the grain refinement mechanism of the nanostructured $\mathrm{Fe}-\mathrm{V}$ $\mathrm{Nb}$ modificators is different from that of the microalloying elements. The nanostructured modificators acting as the nucleation centers can efficiently refine the as-cast grains, and as a result, the austenite composed of finer grains can be obtained in the subsequent heat treatment process.

\subsection{Effect of Fe- $\mathrm{V}-\mathrm{Nb}$ Modificators on the Mechanical Prop-} erties of Steels. Figure 6 shows the effect of alloy elements on the yield strength of specimens tempered at different temperatures. It can be seen from Figure 6 that there is a great difference of the yield strength between steel $\mathrm{B}$

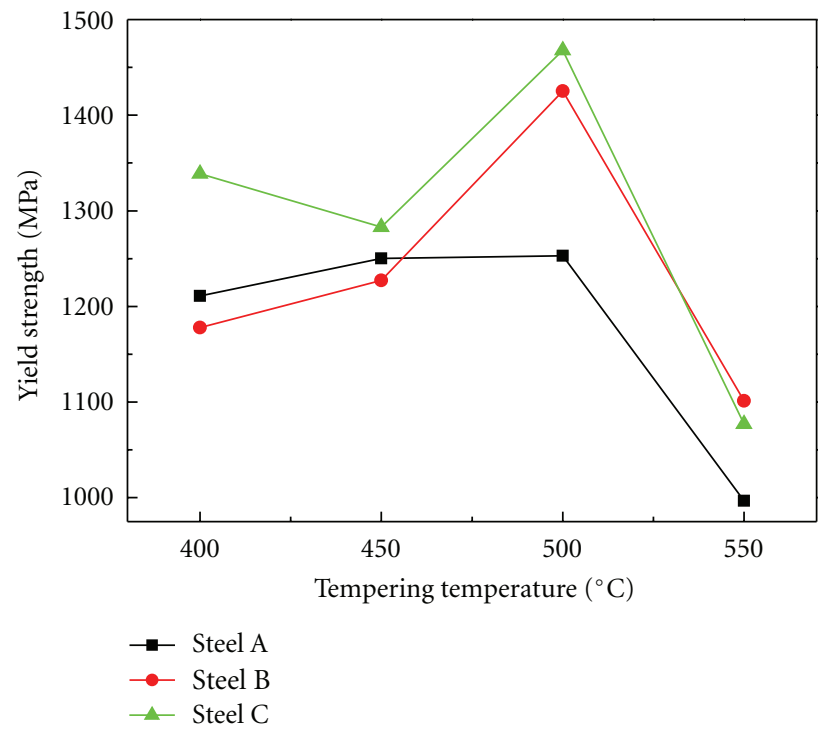

FIgURE 6: Yield-strength as a function of tempering temperature.

and $\mathrm{C}$ at $400^{\circ} \mathrm{C}$, which is because the grain size of steel $\mathrm{C}$ is smaller than steel $\mathrm{B}$. By tempering at $400^{\circ} \mathrm{C}$ the recrystallization of $\alpha$-phase does not yet happen, the grain refinement strengthening plays an important role during this period. The metastable phase $\varepsilon$-carbide particles emerged at lower temperatures $\left(<500^{\circ} \mathrm{C}\right)$ and with improving the tempering temperature, the amount of $\varepsilon$-carbide particles turning to be cementite increases. Because the yield strength 


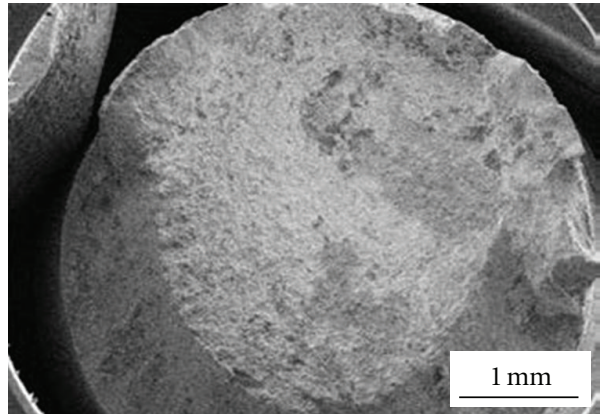

(a)

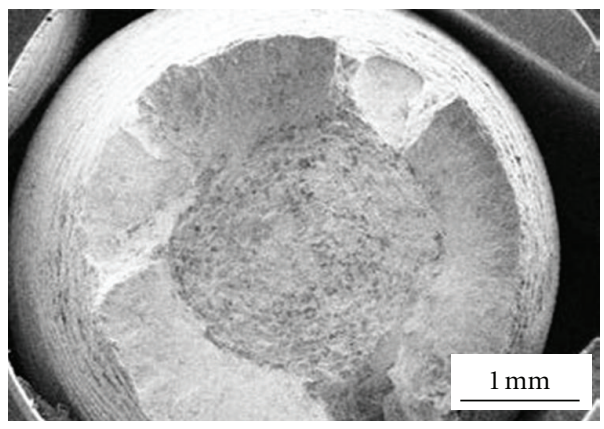

(c)

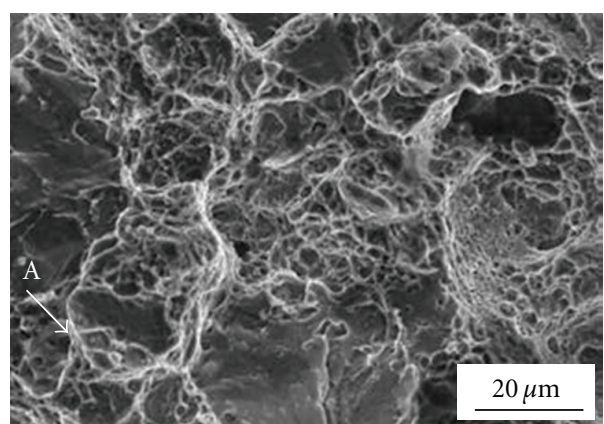

(b)

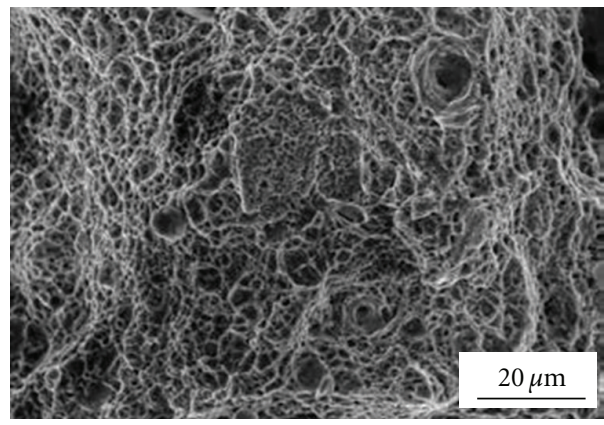

(d)

FIgURE 7: Macroscopic configuration and fracture surface of Steel B and Steel C by tempering at $500^{\circ} \mathrm{C}$.

is greatly affected by the distribution of tempered carbides [9], until the tempering temperature reaches $500^{\circ} \mathrm{C}$, this transformation is completed, leading to the yield strength of three specimens with the maximum value (as seen in Figure 6). With the tempering temperature increasing, the recrystallization of $\alpha$-phase occurs. The supersaturation of $\alpha$-phase decreases and transforms finally to cementite. The recrystallization temperature of steel $\mathrm{C}$ with $\mathrm{Fe}-\mathrm{V}-\mathrm{Nb}$ modificators is higher than steel B. So, by tempering at $500^{\circ} \mathrm{C}$, the yield strength of steel $\mathrm{C}$ is higher than steel $\mathrm{B}$. At the tempering temperature above $500^{\circ} \mathrm{C}$, the decrease of the yield strength is caused by the coarsening of the cementite and the recrystallization of $\alpha$-phase. Under the same temperature, the value of the yield strength is commonly determined by the average grain size. Comparing with steel $\mathrm{B}$, steel $\mathrm{C}$ has a higher yield strength because of the function of the nanostructured Fe-V-Nb modificators. So, it can be deduced that steel $\mathrm{C}$ has a smaller average grain size due to the formation of lots of nucleation centers in the solidification stages of liquid steel.

3.4. Fracture Surface Observations. Figure 7 shows the macroscopic and microscopic fracture surfaces of steels B and C. The fracture surface of steel B is quite smooth with no noticeable area reduction (Figure $7(\mathrm{a})$ ), meanwhile, steel $\mathrm{C}$ exhibits a rough fracture surface with noticeable necking zones (Figure 7(c)). It can be speculated from the macroscopic fracture surfaces that a "cup-cone" feature of steel $\mathrm{C}$ is beneficial to obtaining higher ductility and toughness $[10,11]$. Figures $7(\mathrm{~b})$ and $7(\mathrm{~d})$ show the high-magnification fracture surfaces of steel B and steel C, respectively. From
Figure 7(b), it can be found that the fractures consist of both dimple fracture and cleavage fracture (arrow A). The cleavage fracture is decided by the morphology and size of martensite. The martensite in steel B is much bigger than steel $\mathrm{C}$ and there are a little coarse-grained twin-mastensites, so the cleavage fracture appears in it. Because the propagation of crack commonly appears as river markings, a large proportion of the river markings means the poor toughness. However, the fracture of steel $\mathrm{C}$ is mostly characterized by many uniform and fine dimple depressions being equiaxed or elliptical in shape, which make a clear case of ductile fracture $[12,13]$. At the same time, cleavage facets were not observed. Furthermore, the dimple depression arises from the growth and coalescence of voids around the second phase particles during the deformation. It is known that for the pearlitic-type organizations, the fracture unit is the pearlite (troostite) colony. In this study, the grains of specimens can be efficiently refined by adding $\mathrm{Fe}-\mathrm{V}-\mathrm{Nb}$ modificators which act as the nucleation centers. Consequently, the strength and toughness of the material can be enhanced by virtue of the finer pearlite colony. Among various methods for increasing the strength, grain refinement is the only effective way to improve both the strength and toughness of steels [14]. As mentioned above, the yield strength of steels $\mathrm{C}$ containing Fe-V-Nb modificators is superior to steels $\mathrm{B}$ and a higher toughness is obtained resultantly, making the fracture mode of specimens after the inoculation treatment reveals the characteristics of ductile fracture. 


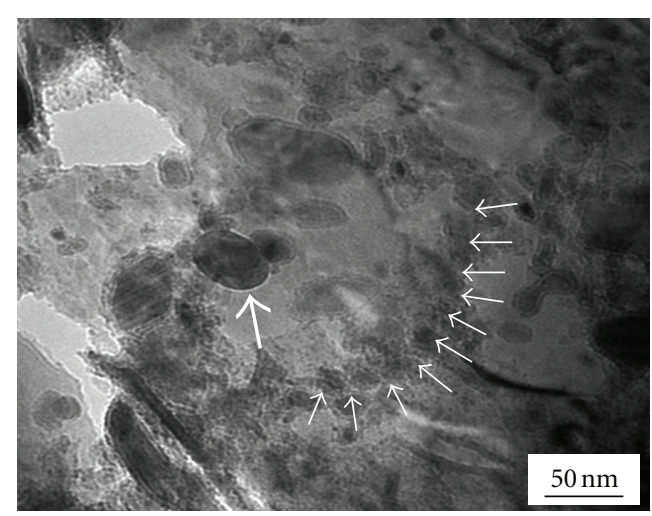

(a)

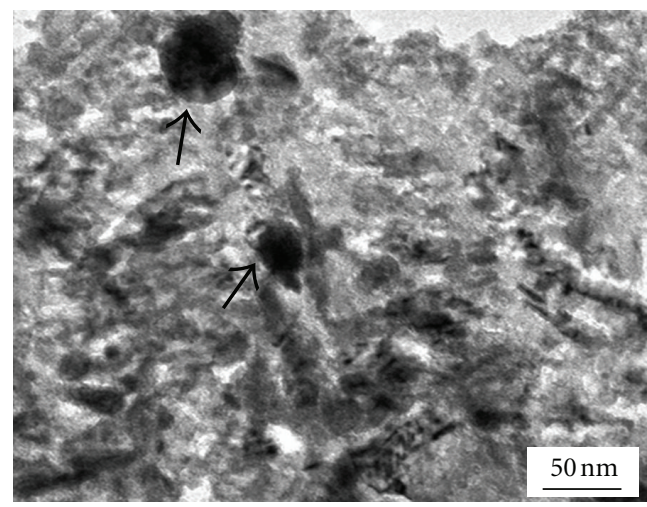

(c)

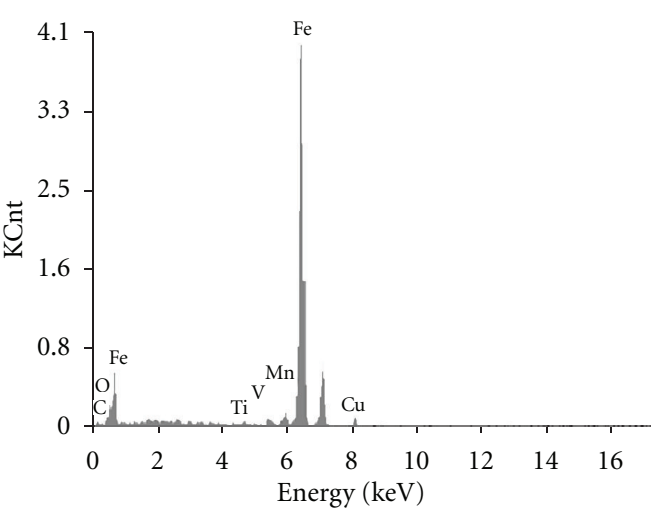

(b)

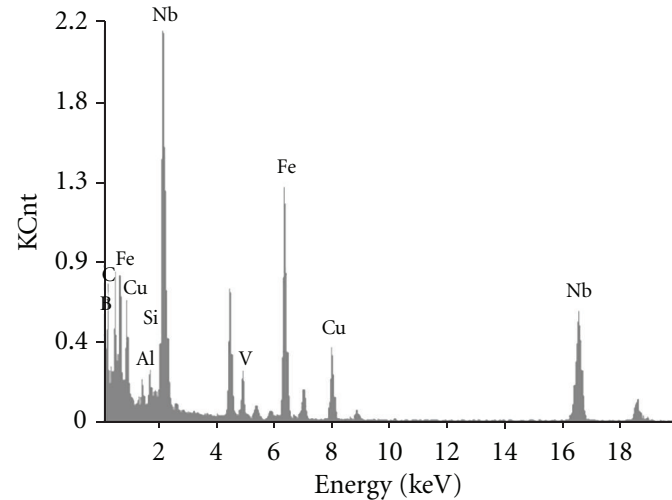

(d)

FIGURE 8: TEM micrographs showing the distribution of precipitates by tempering at $450^{\circ} \mathrm{C}$ : (a) Steel B; (b) EDX analysis on the spheroidal particles in (a); (c) Steel C; (d) EDX analysis on the spheroidal particles in (c).

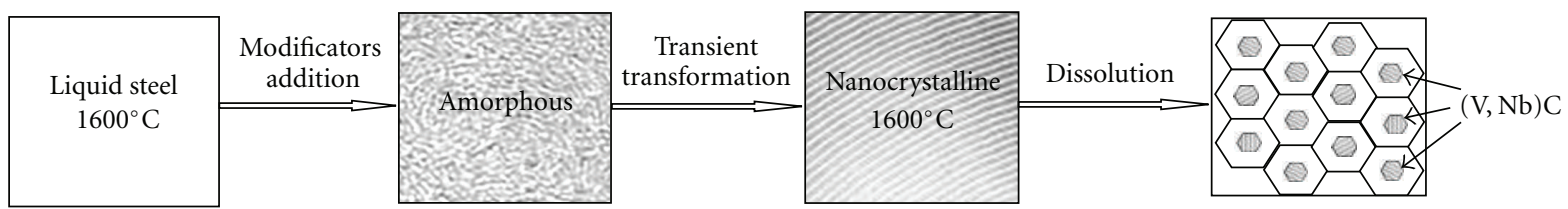

FIgURE 9: Nucleation model of austenite grains: the microstructure evolution of Fe-V-Nb modificators.

3.5. TEM Observations. To determine the action mechanism of microalloying elements and modificators, the microstructure of tempered carbides in steels $\mathrm{B}$ and $\mathrm{C}$ tempered at $500^{\circ} \mathrm{C}$ were investigated, shown in Figure 8 . As seen in it, all types of particles are nearly spherical in shape with a diameter of $15-50 \mathrm{~nm}$. The spheroidal precipitate (marked by the big white arrow in Figure $8(\mathrm{a})$ ) is confirmed as the vanadium carbides by the EDX analysis (Figure 8(b)). Other little spheroidal precipitates (marked by the little white arrow in Figure 8(b)) are speculated to be the vanadium carbides or niobium carbides precipitated at grain boundaries. This phenomenon is well consistent with our earlier research results, in which microalloying elements have the wellknown capability to hinder the growth of austenite grains and produces fine microstructures $[15,16]$. EDX analysis (Figure $8(\mathrm{~d})$ ) shows that the spheroidal particle marked by the big black arrow in Figure $8(\mathrm{c})$ is confirmed as the vanadium and niobium carbides which exist in grains. Above the temperature of $\mathrm{Ac}_{3},(\mathrm{~V}, \mathrm{Nb}) \mathrm{C}$, and the steel are both FCC lattice, so $(\mathrm{V}, \mathrm{Nb}) \mathrm{C}$ and $\gamma$-Fe can keep the coherent structure which lead to reducing the surface energy between them and promote the heterogeneous nucleation. So the vanadium and niobium carbides (marked by the black arrow in Figure 8(c)) observed in steels C can easily become the nucleation centers in the solidification stages. In this study, the amorphous parts of Fe- $\mathrm{V}-\mathrm{Nb}$ modificators added in the steels are in metastable states and rapidly convert into dispersed nanocrystallines. A model for the formation of austenitic in solidification processes is shown in Figure 9. When the thermal conditions are appropriate, the phase transformation driving force is raised and nucleation is promoted. Subsequently, the nucleation of liquid steel is along the nanocrystallines which directly increases the nucleation rate and brings about the refinement of austenite 
grains. It is worth noting that, the grain refinement by virtue of Fe- $\mathrm{V}-\mathrm{Nb}$ modificators can enhance not only the strength but also the toughness of the steel, which is consonant with the experimental results above.

\section{Conclusions}

(1) The microstructure of the steels after quenching consists of the lath martensite and acicular martensite, and the steel modified by $\mathrm{Fe}-\mathrm{V}-\mathrm{Nb}$ modificators has the thinner lath martensite and shorter acicular martensite comparing with the other two testing steels.

(2) The tensile test shows that dimples which represent the ductile fracture appear in the fracture surface of the steel modified by Fe-V-Nb modificators. But the tensile fracture of $\mathrm{V}-\mathrm{Nb}$ microalloyed steel is composed of both quasi cleavages and dimples.

(3) In the steel modified by the Fe-V-Nb modificators, $(\mathrm{V}, \mathrm{Nb}) \mathrm{C}$ compound carbides act as the nucleation centers which directly increase the nucleation rate and result in the refinement of grains.

\section{Acknowledgments}

This research was financially supported by the Key Technology R\&D Program of Hebei Province (no. 09215102D); Scientific and Technical Research in Higher Education of Hebei Province (no. Z2010235). The authors wish to thank the editors and reviewers for their comments and suggestions.

\section{References}

[1] A. Ardehali Barani, D. Ponge, and D. Raabe, "Refinement of grain boundary carbides in a Si-Cr spring steel by thermomechanical treatment," Materials Science and Engineering A, vol. 426, no. 1-2, pp. 194-201, 2006.

[2] J. Fernández, S. Illescas, and J. M. Guilemany, "Effect of microalloying elements on the austenitic grain growth in a low carbon HSLA steel," Materials Letters, vol. 61, no. 11-12, pp. 2389-2392, 2007.

[3] J. P. Wise, J. Spice, S. G. Davidson, W. E. Heitmann, and G. Krauss, "Influence of short austenitizing times on the fracture behavior of a microalloyed automotive spring steel," Scripta Materialia, vol. 44, no. 2, pp. 299-304, 2001.

[4] R. Kuziak, T. Bołd, and Y. W. Cheng, "Microstructure control of ferrite-pearlite high strength low alloy steels utilizing microalloying additions," Journal of Materials Processing Technology, vol. 53, no. 1-2, pp. 255-262, 1995.

[5] A. A. Barani, F. Li, P. Romano, D. Ponge, and D. Raabe, "Design of high-strength steels by microalloying and thermomechanical treatment," Materials Science and Engineering A, vol. 463, no. 1-2, pp. 138-146, 2007.

[6] J. H. Ai, T. C. Zhao, H. J. Gao, Y. H. Hu, and X. S. Xie, "Effect of controlled rolling and cooling on the microstructure and mechanical properties of $60 \mathrm{Si}_{2} \mathrm{MnA}$ spring steel rod," Journal of Materials Processing Technology, vol. 160, no. 3, pp. 390-395, 2005.
[7] C. S. Lee, K. A. Lee, D. M. Li, S. J. Yoo, and W. J. Nam, "Microstructural influence on fatigue properties of a highstrength spring steel," Materials Science and Engineering A, vol. 241, no. 1-2, pp. 30-37, 1998.

[8] A. Khorsand Zak, W. H. Abd. Majid, W. H. Abd. Majid, Ramin Yousefi, and R. Parvizi, "Synthesis, magnetic properties and $\mathrm{X}$-ray analysis of $\mathrm{Zn}_{0.97} \mathrm{X}_{0.03} \mathrm{O}$ nanoparticles $(\mathrm{X}=\mathrm{Mn}, \mathrm{Ni}$, and Co) using Scherrer and sizeestrain plot methods," Solid State Sciences, vol. 144, pp. 88-94, 2012.

[9] S. Fank and M. Demirkol, "Effect of microstructure on the hysteresis performance of force transducers using AISI 4340 steel spring material," Sensors and Actuators A, vol. 126, no. 1, pp. 25-32, 2006.

[10] W. S. Du, R. Cao, Y. J. Yan, Z. L. Tian, Y. Peng, and J. H. Chen, "Fracture behavior of 9\% nickel high-strength steel at various temperatures. Part I. Tensile tests," Materials Science and Engineering A, vol. 486, no. 1-2, pp. 611-625, 2008.

[11] H. Li and F. Ebrahimi, "Tensile behavior of a nanocrystalline Ni-Fe alloy," Acta Materialia, vol. 54, no. 10, pp. 2877-2886, 2006.

[12] I. Dlouhý and B. Strnadel, "The effect of crack propagation mechanism on the fractal dimension of fracture surfaces in steels," Engineering Fracture Mechanics, vol. 75, no. 3-4, pp. 726-738, 2008.

[13] K. Kocatepe, M. Cerah, and M. Erdogan, "The tensile fracture behaviour of intercritically annealed and quenched + tempered ferritic ductile iron with dual matrix structure," Materials and Design, vol. 28, no. 1, pp. 172-181, 2007.

[14] A. Bakkalolu, "Effect of processing parameters on the microstructure and properties of an Nb microalloyed steel," Materials Letters, vol. 56, no. 3, pp. 200-209, 2002.

[15] B. Garbarz, J. Marcisz, and J. Wojtas, "TEM analysis of fine sulphides dissolution and precipitation in steel," Materials Chemistry and Physics, vol. 81, no. 2-3, pp. 486-489, 2003.

[16] A. Kammouni, W. Saikaly, M. Dumont, C. Marteau, X. Bano, and A. Charaï, "Effect of the bainitic transformation temperature on retained austenite fraction and stability in Ti microalloyed TRIP steels," Materials Science and Engineering A, vol. 518, no. 1-2, pp. 89-96, 2009. 

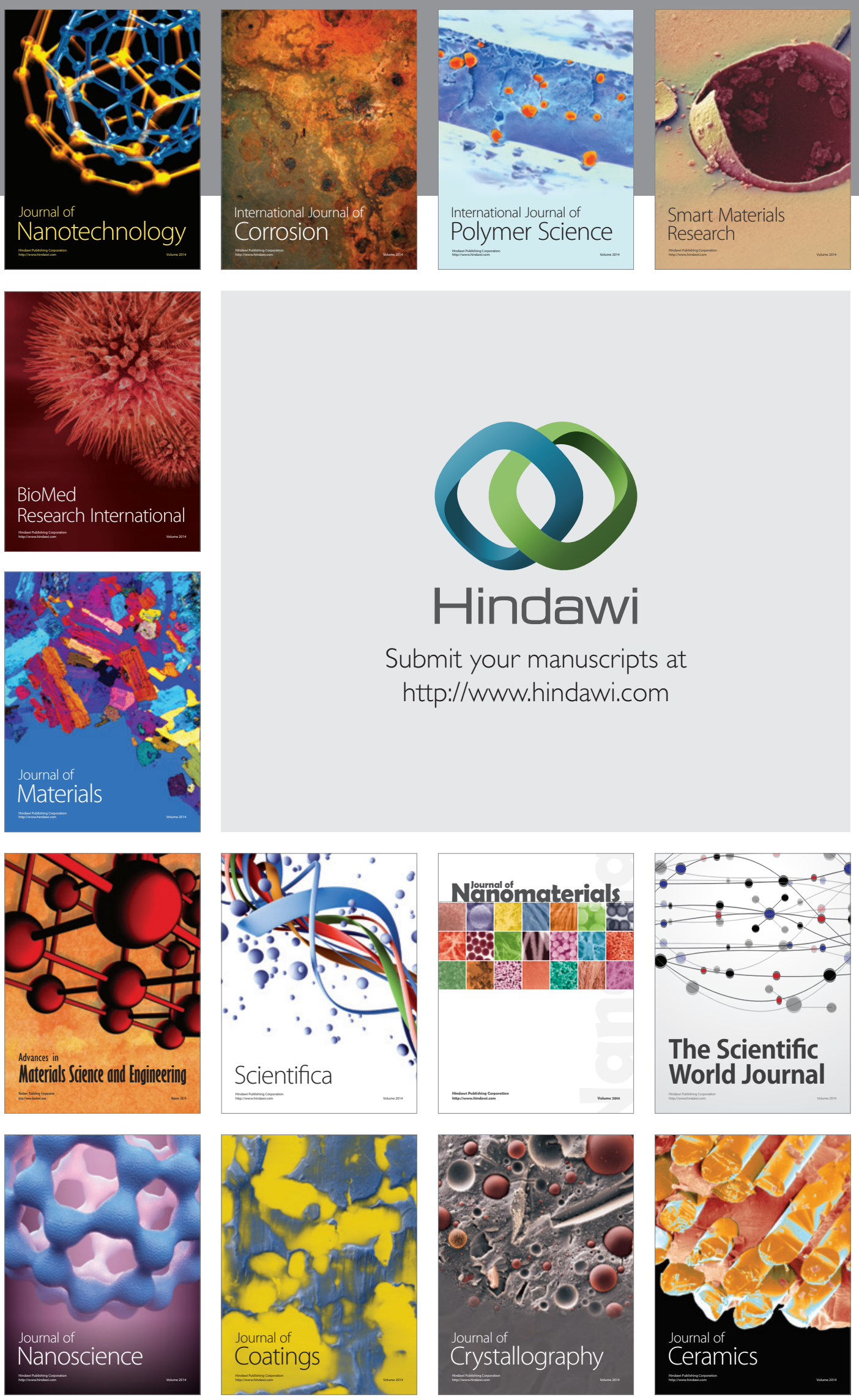

The Scientific World Journal

Submit your manuscripts at

http://www.hindawi.com

\section{World Journal}

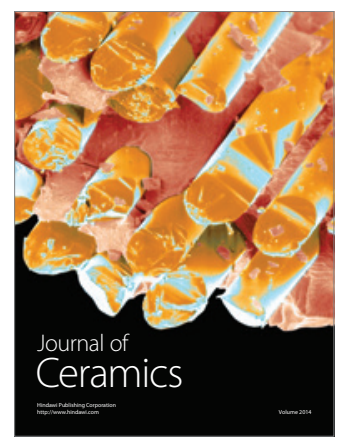

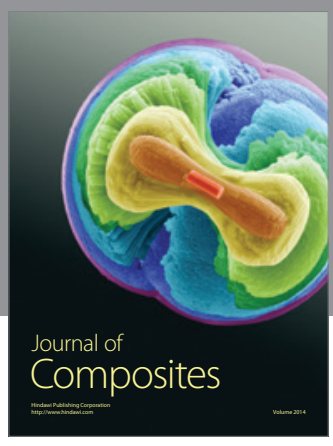
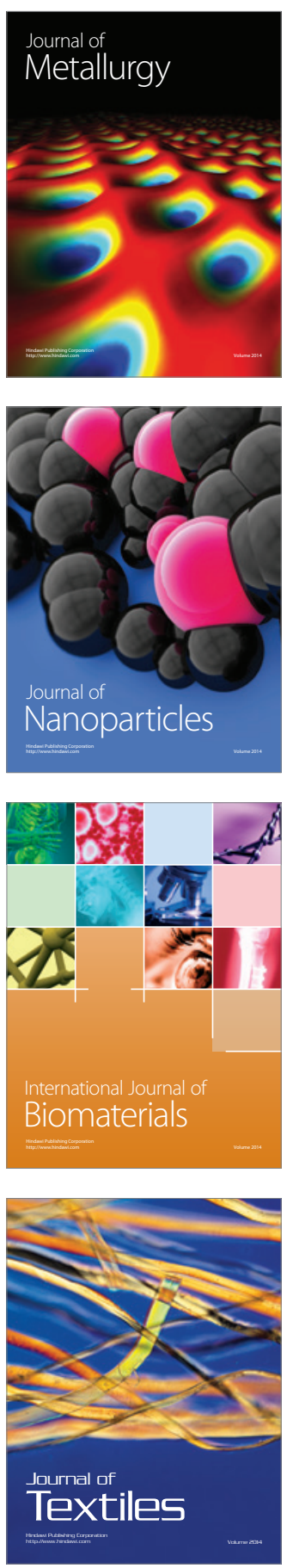